\title{
Association between $A B C B 1$ genetic polymorphism and the effect on epilepsy following phenytoin treatment
}

\author{
FEI SUN ${ }^{1}$, BO-QIANG CAO ${ }^{1}$, BO WANG $^{1}$, SHI-QIANG WU ${ }^{2}$ and DE-HUA JIANG ${ }^{1}$ \\ Departments of ${ }^{1}$ Neurosurgery and ${ }^{2}$ Pharmacy, Xuzhou Central Hospital, Xuzhou, Jiangsu 221009, P.R. China
}

Received December 11, 2015; Accepted July 26, 2016

DOI: $10.3892 / \mathrm{etm} .2016 .3553$

\begin{abstract}
The aim of the study was to analyze the effect of $A B C B 1$ genetic polymorphisms on the efficacy of phenytoin (PHT) treatment in epilepsy patients. In total, 200 epilepsy patients who were administered PHT were divided into the responsive and pharmaco-resistance groups depending on the clinical data of PHT treatment in epilepsy patients. The serum concentration of PHT was detected by high-performance liquid chromatography (HPLC). $A B C B 1$ polymorphisms were analyzed by the polymerase chain reaction restriction-fragment length polymorphism method. The C1236T, C3435T and $\mathrm{G} 2677 \mathrm{~T} / \mathrm{A}$ haplotypes were reconstructed for the $A B C B 1$ gene using SHEsis programs. One-way analysis of variance was used for data analysis. In $A B C B 1 \mathrm{C} 1236 \mathrm{~T}$, the rate of the $\mathrm{CC}$ genotype in pharmaco-resistance $(17.5 \%)$ was higher than that of the responsive group (2.1\%), while the rate of the TT genotype in pharmaco-resistance $(41.6 \%)$ was lower than that of the responsive group $(55.4 \%)(\mathrm{P}<0.05)$. In $A B C B 1$ G2677T/A, the rate of the GG genotype in pharmaco-resistance $(29.6 \%)$ was higher than that of the responsive group $(9.7 \%)$, while the rate of the TT genotype in pharmaco-resistance $(4.6 \%)$ was lower than that of the responsive group $(30.4 \%)(\mathrm{P}<0.05)$. The rate of the TTC haploid in pharmaco-resistance $(24.1 \%)$ was higher than that of the responsive group $(8.8 \%)(\mathrm{P}<0.05)$. The PHT serum concentration had no statistical significance in the patients with different genotypes. In conclusion, there was no association between $A B C B 1$ genetic polymorphism and PHT serum concentration, although the polymorphisms affected the efficacy of PHT treatment in patients with epilepsy.
\end{abstract}

\section{Introduction}

Epilepsy is a recurrent neurological disease caused by a variety of factors. It is characterized by its high incidence,

Correspondence to: Dr De-Hua Jiang, Department of Neurosurgery, Xuzhou Central Hospital, 199 Jiefang Road, Xuzhou, Jiangsu 221009, P.R. China

E-mail: rcr794@163.com

Key words: epilepsy, ABCB1 gene, phenytoin, genetic polymorphism long duration and low healing rate (1). The age-adjusted prevalence in the general population has been estimated to range between 2.2 and 41.0 per 1,000 individuals annually, while the age-adjusted incidence is between 16 and 51 per 100,000 individuals. However, the annual incidence rate surpasses $0.1 \%$, and increases with age in the elderly population, while the cumulative incidence up to 80 years of age lies in the range of $1.3-4.0 \%$. At present, the clinical treatment of the disease is mainly dependent on the rational use of antiepileptic drugs $(2,3)$.

In 2003, Siddiqui et al (4) conducted a study on the relationship of $A B C B I$ genetic polymorphism and drug-resistant epilepsy. In total, 315 epileptics were selected to receive phenytoin (PHT) treatment and the results showed that the proportion of $\mathrm{CC}$ genotype of $A B C B l$ gene $\mathrm{C} 1236 \mathrm{~T}$ in drug-resistant epileptics was higher than that in drug-sensitive patients (27.5 and $15.7 \%$, respectively). However, the proportion of TT genotype was significantly lower than that in drug-sensitive patients (19.5 and 29.6\%, respectively). Zimprich et al (5) found that the haplotype that was composed of C1236T, C3435T and G2677T/A was associated with drug-resistant epilepsy. Hung et al (6) also found that the polymorphism of G2677T and C3435T of the $A B C B 1$ gene was associated with drug-resistant epilepsy. However, other investigators reported opposite findings (7-10). Therefore, whether there is a correlation between the polymorphism of $A B C B 1$ and the efficacy of antiepileptic drugs remains controversial.

In the present study, we investigated the effect of $A B C B I$ genetic polymorphisms on the efficacy of PHT treatment in epileptic patients.

\section{Materials and methods}

Instruments and reagents. Taq DNA polymerase, dNTP, polymerase chain reaction (PCR) buffer, restriction enzymes SamI, BamH and KipI were all purchased from Bao Biotechnology (Dalian) Co., Ltd. (Dalian, China), and primers were produced by Shanghai YingWei Chuang Jin Co., Ltd. (Shanghai, China). The TDxFLx Highly effective blood concentration detector was purchased from Abbott A.G. (Baar, Switzerland), PHT sodium kits from Abbott Laboratories, PCR thermal cycler from Applied Biosystems Life Technologies (GeneAmp 9700 type; Foster City, CA, USA), and low temperature and high speed centrifuge from Beckman Coulter, Inc. (Brea, CA, USA). 
Table I. Genetic equilibrium test on the three SNPs of patients in epileptic drug resistance group.

\begin{tabular}{|c|c|c|c|c|c|}
\hline SNPs & Genotype & Observation Value & Expected value & $\chi^{2}$ & P-value \\
\hline $\mathrm{C} 1236 \mathrm{~T}$ & $\begin{array}{l}\mathrm{CC} \\
\mathrm{CT} \\
\mathrm{TT}\end{array}$ & $\begin{array}{l}19 \\
44 \\
45\end{array}$ & $\begin{array}{l}15.56481 \\
50.87037 \\
41.56481\end{array}$ & 1.97 & 0.16 \\
\hline $\mathrm{C} 3435 \mathrm{~T}$ & $\begin{array}{l}\mathrm{CC} \\
\mathrm{CT} \\
\mathrm{TT}\end{array}$ & $\begin{array}{l}45 \\
50 \\
13\end{array}$ & $\begin{array}{l}45.37037 \\
49.25926 \\
13.37037\end{array}$ & 0.024 & 0.876 \\
\hline G2677T/A & $\begin{array}{l}\text { AA } \\
\text { AG } \\
\text { GG } \\
\text { GT } \\
\text { TA }\end{array}$ & $\begin{array}{r}2 \\
15 \\
32 \\
40 \\
14\end{array}$ & $\begin{array}{c}2.266311 \\
17.39942 \\
33.39567 \\
35.92139 \\
9.271028\end{array}$ & 5.543 & 0.136 \\
\hline
\end{tabular}

SNP, single nucleotide polymorphism.

Patients. The epileptics included in the study were outpatients or inpatients of the Department of Neurosurgery, Xuzhou Central Hospital, Affiliated Hospital of Southeast University (Xuzhou, China). The patients were administered PHT sodium over one year. There were 200 cases, including 137 men and 63 women, the youngest being 18 and the oldest 76 years of age.

Efficacy grouping. Drug-resistant epilepsy was defined as indicated by Shahwan et al (10). The drug-resistant group comprised 108 patients accepted for formal antiepileptic drug therapy, with blood drug concentration either at effectively higher concentration or having reached the commonly used maximum dose, albeit there was no reduction in seizure frequency by $50 \%$. The control group comprised 92 patients accepted for formal antiepileptic drug therapy, with blood drug concentration either at effectively higher concentration or having reached the commonly used maximum dose, without any attack or attack within 1 year or seizure frequency $<50 \%$.

Sample collection. Peripheral venous blood samples $(6 \mathrm{ml})$ were collected from the participants. The blood specimens were divided into two sections, of which $2 \mathrm{ml}$ was transferred into the EDTA anticoagulant tube (used for DNA extraction) and $4 \mathrm{ml}$ was transferred into an ordinary biochemical tube. The biochemical tubes were immediately centrifuged at $4,000 \mathrm{x} g$ for $5 \mathrm{~min}$ after collection, and the upper plasma was transferred into the clean tube. Samples were stored at $-80^{\circ} \mathrm{C}$.

ABCB1 genotyping. The mononucleotides of C1236T, C3435T, and G2677T/A, which were the common sites of ABCB1 were detected using the PCR-fragment length polymorphism method and verified with DNA sequencing. SHEsis software (http://anal-ysis.bio-x.cn) was applied to deduce the haplotype frequency comprising C1316T, C3435T and G2677T/A of ABCBI and the difference was compared.

Detection of plasma drug concentration. The PHT concentration in plasma was detected using high-performance liquid chromatography. The chromatographic conditions were: Chromatographic column from Ultimate ${ }^{\mathrm{TM}}$ AQ-C18 chromatographic column (Thermo Fisher Scientific, Waltham, MA, USA); column temperature at $40^{\circ} \mathrm{C}$; mobile phase was acetonitrile/ammonium acetate solution (containing $0.25 \%$ formic acid) at 50:50; flow velocity was $1.0 \mathrm{ml} / \mathrm{min}$; wavelength measurement was $220 \mathrm{~nm}$; and AUFS was 0.2. For the plasma samples, $0.2 \mathrm{ml}$ samples were taken and added into tubes, then $50 \mu \mathrm{l}$ alprazolam solution was added as internal reference. Subsequently, $5 \mathrm{ml}$ of ether was added after blending, vortexing and agitation for $3 \mathrm{~min}$ and then centrifuged at $3,000 \mathrm{x} \mathrm{g}$ for $5 \mathrm{~min}$. The supernatant was then transferred into another clean tube at $40^{\circ} \mathrm{C}, 100 \mu 1$ mobile phase was used for constant volume of the residue, followed by an injection of $20 \mu 1$.

Statistical analysis. SPSS 17.0 (SPSS, Inc., Chicago, IL, USA) was used to perform statistical analysis. The Chi-square test and analysis of variance were used to compare between groups. The Hardy-Weinberg law of genetic equilibrium was used to detect whether the allele frequency was in accordance with the law of population genetics. All the tests were two-tailed. $\mathrm{P}<0.05$ was considered to indicate a statistically significant difference.

\section{Results}

Genetic equilibrium test. A total of 200 cases were included in the present study and were divided into the drug-resistant group $(n=108)$ and control group $(n=92)$ according to the patients' clinical data and definition of drug resistance. To prove the representativeness of alleles, we performed the Hardy-Weinberg genetic equilibrium test on the genotype and allele of the two groups of patients (Tables I and II). All three single-nucleotide polymorphisms (SNPs) were consistent with the Hardy-Weinberg ratio $(\mathrm{P}>0.05)$, which indicated that the research subjects were representative of entire group.

Effect of $A B C B 1$ polymorphisms on the in vivo concentration of PHT. The patients were grouped according to the $A B C B 1$ C1236T, C3435T and G2677T/A genotypes, and the effect of $A B C B 1$ polymorphisms was observed on the in vivo concentration of PHT in each group of patients. The results showed that 
Table II. Genetic equilibrium test on the three SNPs of patients in the epileptic control group.

\begin{tabular}{|c|c|c|c|c|c|}
\hline SNPs & Genotype & Observation value & Expected value & $\chi^{2}$ & P-value \\
\hline $\mathrm{C} 1236 \mathrm{~T}$ & $\begin{array}{l}\text { CC } \\
\mathrm{CT} \\
\mathrm{TT}\end{array}$ & $\begin{array}{r}2 \\
39 \\
51\end{array}$ & $\begin{array}{c}5.024457 \\
32.95109 \\
54.02446\end{array}$ & 3.1 & 0.078 \\
\hline $\mathrm{C} 3435 \mathrm{~T}$ & $\begin{array}{l}\mathrm{CC} \\
\mathrm{CT} \\
\mathrm{TT}\end{array}$ & $\begin{array}{r}37 \\
49 \\
6\end{array}$ & $\begin{array}{l}41.11141 \\
40.77717 \\
10.11141\end{array}$ & 3.741 & 0.053 \\
\hline G2677T/A & $\begin{array}{l}\text { AA } \\
\text { AG } \\
\text { GG } \\
\text { GT } \\
\text { TA } \\
\text { TT }\end{array}$ & $\begin{array}{r}1 \\
11 \\
9 \\
32 \\
11 \\
28\end{array}$ & $\begin{array}{c}1.45325 \\
7.708561 \\
10.22222 \\
33.18033 \\
12.44262 \\
26.92502\end{array}$ & 1.945 & 0.584 \\
\hline
\end{tabular}

SNP, single-nucleotide polymorphism.

Table III. The plasma concentration of phenytoin sodium and comparisons among different genotypes of C1236T.

\begin{tabular}{lcccc}
\hline & \multicolumn{4}{c}{ Genotype } \\
\cline { 2 - 4 } $\begin{array}{l}\text { PHT } \\
\text { concentration }\end{array}$ & $\begin{array}{c}\mathrm{CC} \\
(\mathrm{n}=21)\end{array}$ & $\begin{array}{c}\mathrm{CT} \\
(\mathrm{n}=83)\end{array}$ & $\begin{array}{c}\mathrm{TT} \\
(\mathrm{n}=96)\end{array}$ & P-value \\
\hline PHT S, $\mu \mathrm{g} / \mathrm{ml}$ & $0.72 \pm 0.56$ & $1.17 \pm 0.69$ & $1.63 \pm 1.21$ & 0.231 \\
\hline
\end{tabular}

PHT S, phenytoin serum.
Table IV. The plasma concentration of phenytoin sodium and comparisons among different genotypes of C3435T.

\begin{tabular}{lcccc}
\hline & \multicolumn{4}{c}{ Genotype } \\
\cline { 2 - 4 } $\begin{array}{l}\text { PHT } \\
\text { concentration }\end{array}$ & $\begin{array}{c}\mathrm{CC} \\
(\mathrm{n}=82)\end{array}$ & $\begin{array}{c}\mathrm{CT} \\
(\mathrm{n}=99)\end{array}$ & $\begin{array}{c}\mathrm{TT} \\
(\mathrm{n}=19)\end{array}$ & P-value \\
\hline PHT S, $\mu \mathrm{g} / \mathrm{ml}$ & $1.32 \pm 0.26$ & $1.26 \pm 0.42$ & $1.51 \pm 0.83$ & 0.231 \\
\hline
\end{tabular}

PHT S, phenytoin serum.

Table V. The plasma concentration of phenytoin sodium and comparisons among different genotypes of G2677T/A.

\begin{tabular}{llllllll}
\hline & \multicolumn{5}{c}{ Genotype } \\
\cline { 2 - 7 } PHT concentration & AA $(\mathrm{n}=3)$ & AG $(\mathrm{n}=28)$ & $\mathrm{GG}(\mathrm{n}=39)$ & $\mathrm{GT}(\mathrm{n}=72)$ & $\mathrm{TA}(\mathrm{n}=25)$ & TT $(\mathrm{n}=33)$ & $\mathrm{P}-\mathrm{value}$ \\
\hline PHT S, $\mu \mathrm{g} / \mathrm{ml}$ & $1.20 \pm 1.01$ & $1.35 \pm 0.92$ & $0.82 \pm 0.56$ & $1.13 \pm 0.86$ & $1.28 \pm 1.00$ & $1.71 \pm 1.46$ & 0.169 \\
\hline
\end{tabular}

PHT S, phenytoin serum.

differences among all the groups on serum concentration of PHT were not statistically significant $(\mathrm{P}>0.05)$ (Tables III-V).

Comparison of the distribution frequency of different genotypes in three SNPs loci of the two groups of epileptic patients. As shown in Table VI, differences in the distribution frequency of different genotypes in C1236T and G2677T/A loci were statistically significant $(\mathrm{P}<0.05)$. In $\mathrm{C} 1236 \mathrm{~T}$ locus, the proportion of the CC genotype in the drug-resistant group was $17.5 \%$, which was higher than that in the control group (2.1\%); the proportion of the TT genotype in the control group was $55.4 \%$, which was higher than that in the drug-resistant group $41.6 \%(\mathrm{P}=0.001)$. In G2677T/A locus, the proportion of the GG genotype in the drug-resistant group was $29.6 \%$, which was higher than that in control group (9.7\%); the proportion of the TT genotype in the control group was $30.4 \%$, which was higher than that in the drug-resistant group 4.6\% ( $\mathrm{P}<0.001)$. In C3435T locus, the distribution frequency between the drug-resistant group and the control group in the Xuzhou region was not statistically significant $(\mathrm{P}=0.349)$.

Comparison of the distribution frequency of different alleles in three SNPs loci of the two groups of epileptic patients. As shown in Table VII, in C1236T locus, the difference between the two groups in the distribution frequency of different alleles was statistically significant $(\mathrm{P}=0.02)$. The distribution frequency of $\mathrm{C}$ allele in the drug-resistant group was higher than that in the control group (37.9 and $23.3 \%$, respectively) while the T allele in the control group was higher than that in the drug-resistance group (76.6 and 62.0\%, individually). In G2677T/A locus, the 
Table VI. Comparison of the distribution frequency of different genotypes in three SNPs loci of the two groups of epileptic patients.

\begin{tabular}{|c|c|c|c|c|c|}
\hline SNPs & Genotype & Drug-resistant group (\%), $\mathrm{n}=108$ & Control group $(\%), \mathrm{n}=92$ & $\chi^{2}$ & P-value \\
\hline \multirow[t]{3}{*}{$\mathrm{C} 1236 \mathrm{~T}$} & $\mathrm{CC}$ & $19(17.5)$ & $2(2.1)$ & \multirow[t]{3}{*}{13.242} & \multirow[t]{3}{*}{0.001} \\
\hline & CT & $44(40.7)$ & $39(42.3)$ & & \\
\hline & $\mathrm{TT}$ & $45(41.6)$ & $51(55.4)$ & & \\
\hline \multirow[t]{3}{*}{ C3435T } & $\mathrm{CC}$ & $45(41.6)$ & $37(40.2)$ & \multirow[t]{3}{*}{2.103} & \multirow[t]{3}{*}{0.349} \\
\hline & CT & $50(46.2)$ & $49(53.2)$ & & \\
\hline & TT & $13(12.0)$ & $6(6.5)$ & & \\
\hline \multirow[t]{6}{*}{ G2677T/A } & AA & $2(1.8)$ & $1(1.0)$ & \multirow[t]{6}{*}{30.23} & \multirow[t]{6}{*}{$<0.001$} \\
\hline & $\mathrm{AG}$ & $15(13.8)$ & $11(12.0)$ & & \\
\hline & GG & $32(29.6)$ & $9(9.7)$ & & \\
\hline & GT & $40(37.0)$ & $32(34.7)$ & & \\
\hline & TA & $14(12.9)$ & $11(11.9)$ & & \\
\hline & $\mathrm{TT}$ & $5(4.6)$ & $28(30.4)$ & & \\
\hline
\end{tabular}

SNP, single-nucleotide polymorphism.

Table VII. Comparison of the distribution frequency of different alleles in three SNPs loci of the two groups of epileptic patients.

\begin{tabular}{lrrrr}
\hline SNPs & $\begin{array}{r}\text { Allele } \\
\mathrm{n}=108\end{array}$ & $\begin{array}{c}\text { Drug-resistant } \\
\text { group (\%), n=92 }\end{array}$ & $\begin{array}{c}\text { Control } \\
\text { group (\%) }\end{array}$ & P-value \\
\hline C1236T & $\mathrm{C}$ & $82(37.9)$ & $43(23.3)$ & 0.002 \\
& $\mathrm{~T}$ & $134(62.0)$ & $141(76.6)$ & \\
C3435T & $\mathrm{C}$ & $140(64.8)$ & $123(66.8)$ & 0.674 \\
& $\mathrm{~T}$ & $76(35.1)$ & $61(33.1)$ & \\
G2677T/A & $\mathrm{T}$ & $64(29.6)$ & $99(53.8)$ & $<0.001$ \\
& $\mathrm{~A}$ & $33(15.2)$ & $26(14.1)$ & \\
& $\mathrm{G}$ & $119(55.0)$ & $59(32.0)$ & \\
\hline
\end{tabular}

SNP, single-nucleotide polymorphism.

Table VIII. Comparison of the common haplotype frequency composed in loci C1316T, C3435T and G2677T/A of ABCBI between the two groups of epileptic patients.

\begin{tabular}{llll}
\hline Haplotype & $\begin{array}{c}\text { Drug-resistant } \\
\text { group (\%) }\end{array}$ & $\begin{array}{c}\text { Control } \\
\text { group (\%) }\end{array}$ & P-value \\
\hline CTC & $15.30(7.1)$ & $18.94(10.3)$ & 0.335523 \\
TGC & $47.92(22.2)$ & $39.09(21.2)$ & 0.537572 \\
TTC & $19.05(8.8)$ & $44.35(24.1)$ & 0.0000474 \\
TTT & $23.23(10.8)$ & $25.22(13.7)$ & 0.496837 \\
\hline
\end{tabular}

distribution frequency of the $\mathrm{G}$ allele in the drug-resistant group was higher than that in the control group (55.0 and 32.0\%, respectively) while the $\mathrm{T}$ allele in the control group was higher than that in the drug-resistant group (53.8 and 29.6\%, respectively). Differences were statistically significant $(\mathrm{P}<0.001)$. In $\mathrm{C} 3435 \mathrm{~T}$ locus, the difference in the distribution frequency in the two groups was not statistically significant $(\mathrm{P}=0.674)$.
Comparison of the haplotype frequency composed in the C1316T, C3435T and G2677T/A loci of ABCBI between the two groups of epileptic patients. We employed SHEsis software to deduce the haplotype frequency comprising C1316T, C3435T and G2677T/A of ABCBI. As shown in Table VIII, the frequency of TTC haplotype in control group was significantly higher than that in the drug-resistant group $(\mathrm{P}=0.0000474)$.

\section{Discussion}

Epilepsy is a neurological disease of recurrent seizures with various causes, and has the characteristics of high incidence, long duration and low cure rate (1).

Clinical treatment of the disease includes rational and long-term use of anti-epilepsy drugs. Although PHT is a first-line anti-epileptic drug, its efficacy remains to be confirmed (11). Previous studies suggested that multidrug transporter theory, which leads to function changes of its coding protein, is an important factor resulting in different effectiveness of PHT in treating epilepsy $(12,13)$.

$A B C B 1$ gene codes the protein of $\mathrm{P}-\mathrm{gp}$ and directly regulates its expression and functions. In the central nervous system, P-gp is mainly expressed in the endothelial cells of the blood brain barrier. It can be transported to the blood from brain tissue by itself, thus reducing the level of the drug in the cell. In recent years, investigations on P-gp and drug resistance of epilepsy have become hot spots in this field (14-20). In 2003, Siddiqui et al found that, the polymorphism of C3435T locus of $A B C B 1$ was correlated with the drug resistance of epilepsy, the $C C$ genotype was correlated with drug resistance of epilepsy and the TT genotype was correlated with Anderson-Fabry disease sensitivity (4). In the present study, we have found that the polymorphisms of C3435T, C1316T and G2677T/A locus were relevant to the drug resistance of epilepsy. The results obtained in the present study are therefore contradictory to those of Siddiqui et al (4). The reason for the discrepancy may be due to difference in region, race, definition of drug resistance, the number of samples, and the method of gene detection. Another possible reason is that SNP 
in a single locus was not associated with the presence of drug resistance (9). Thus, a combined effect of SNPs affected the functions of P-gp.

The three SNPs in loci C1236T, G2677T/A and C3435T of $A B C B 1$ gene are closely connected (21). In the present study, we performed common haplotype construction using SHEsis software on the three adjacent loci. Haplotype is the combination of single nucleotide polypeptides that are located and interconnected in a specific region of chromosome and that tend to pass down to the descendants via overall heredity. Most chromosomal regions have only a few common haplotypes (each with $\geq 5 \%$ frequency), which represent the majority of polymorphism between men and women in a group (22). The identification of haplotype is usually dependent on a group of SNP, i.e., a group of SNPs in a specific region of chromosome. At present, haplotype data are obtained by statistical calculation, which is based on the distribution frequency of the genotypes in the population (22). In the present study, SHEsis software was used based on the maximum likelihood algorithm to produce the haploid inference. The results showed that the distribution frequency of TTC haplotype in the epilepsy control group was higher than that in the drug-resistant group. However, the findings of Zimprich et al, Vahab et al and Haerian et al and others did not show that haplotype of the $A B C B 1$ gene was associated with drug resistance $(5,7,22)$. Their findings were contrary to the results obtained in the present study. The discrepancies may be associated with the differences in gender, region and definition of drug resistance of epilepsy. Therefore, it is necessary to expand the sample size to validate the present results.

In conclusion, whether SNPs or haplotype of $A B C B 1$ gene is associated with the drug resistance of epilepsy or not remains to be elucidated. This type of controversy involves objective and subjective factors. Objective factors include gender and region differences that cannot be corrected, while the subjective factors include the fact that investigators do not have a unified definition on drug resistance of epilepsy and that the patients themselves have great subjectivity in expressing their state of illness. Thus, it is crucila to identify a biomarker of drug resistance of epilepsy to avoid the effect of subjective factors.

\section{Acknowledgements}

The present study was supported by the Technology Bureau, Xuzhou city (Jiangsu, China), grand no. XZZDY1306.

\section{References}

1. Werhahn KJ: Epilepsy in the elderly. Dtsch Arztebl Int 106: 135-142, 2009.

2. Banerjee PN, Filippi D and Allen Hauser W: The descriptive epidemiology of epilepsy-a review. Epilepsy Res 85: 31-45, 2009.

3. Benn EK, Hauser WA, Shih T, Leary L, Bagiella E, Dayan P, Green R, Andrews H, Thurman DJ and Hesdorffer DC: Estimating the incidence of first unprovoked seizure and newly diagnosed epilepsy in the low-income urban community of Northern Manhattan, New York City. Epilepsia 49: 1431-1439, 2008.

4. Siddiqui A, Kerb R, Weale ME, Brinkmann U, Smith A, Goldstein DB, Wood NW and Sisodiya SM: Association of multidrug resistance in epilepsy with a polymorphism in the drug-transporter gene ABCB1. N Engl J Med 348: 1442-1448, 2003.
5. Zimprich F, Sunder-Plassmann R, Stogmann E, Gleiss A, Dal-Bianco A, Zimprich A, Plumer S, Baumgartner C and Mannhalter C: Association of an ABCB1 gene haplotype with pharmacoresistance in temporal lobe epilepsy. Neurology 63: 1087-1089, 2004

6. Hung CC, Tai JJ, Lin CJ, Lee MJ and Liou HH: Complex haplotypic effects of the ABCB1 gene on epilepsy treatment response. Pharmacogenomics 6: 411-417, 2005.

7. Vahab SA, Sen S, Ravindran N, Mony S, Mathew A, Vijayan N, Nayak G, Bhaskaranand N, Banerjee M and Satyamoorthy K: Analysis of genotype and haplotype effects of ABCB1 (MDR1) polymorphisms in the risk of medically refractory epilepsy in an Indian population. Drug Metab Pharmacokinet 24: 255-260, 2009.

8. Szoeke C, Sills GJ, Kwan P, Petrovski S, Newton M, Hitiris N, Baum L, Berkovic SF, Brodie MJ, Sheffield LJ, et al: Multidrug-resistant genotype (ABCB1) and seizure recurrence in newly treated epilepsy: Data from international pharmacogenetic cohorts. Epilepsia 50: 1689-1696, 2009.

9. Lakhan R, Misra UK, Kalita J, Pradhan S, Gogtay NJ, Singh MK and Mittal B: No association of ABCB1 polymorphisms with drug-refractory epilepsy in a north Indian population. Epilepsy Behav 14: 78-82, 2009.

10. Shahwan A, Murphy K, Doherty C, Cavalleri GL, Muckian C, Dicker P, McCarthy M, Kinirons P, Goldstein D and Delanty N: The controversial association of ABCB1 polymorphisms in refractory epilepsy: An analysis of multiple SNPs in an Irish population. Epilepsy Res 73: 192-198, 2007.

11. Seager J, Jamison DL, Wilson J, Hayward AR and Soothill JF: IgA deficiency, epilepsy, and phenytoin treatment. Lancet 2: 632-635, 1975.

12. Kotsopoulos IA, van Merode T, Kessels FG, de Krom MC and Knottnerus JA: Systematic review and meta-analysis of incidence studies of epilepsy and unprovoked seizures. Epilepsia 43: 1402-1409, 2002.

13. Kwan P and Brodie MJ: Potential role of drug transporters in the pathogenesis of medically intractable epilepsy. Epilepsia 46: 224-235, 2005.

14. Dombrowski SM, Desai SY, Marroni M, Cucullo L, Goodrich K, Bingaman W, Mayberg MR, Bengez L and Janigro D: Overexpression of multiple drug resistance genes in endothelial cells from patients with refractory epilepsy. Epilepsia 42: 1501-1506, 2001.

15. Rizzi M, Caccia S, Guiso G, Richichi C, Gorter JA, Aronica E, Aliprandi M, Bagnati R, Fanelli R, D'Incalci M, et al: Limbic seizures induce P-glycoprotein in rodent brain: Functional implications for pharmacoresistance. J Neurosci 22: 5833-5839, 2002.

16. Sisodiya S: Drug resistance in epilepsy: Not futile, but complex? Lancet Neurol 2: 331, 2003.

17. Bodó A, Bakos E, Szeri F, Váradi A and Sarkadi B: The role of multidrug transporters in drug availability, metabolism and toxicity. Toxicol Lett 140-141: 133-143, 2003.

18. MacDonald RL, Rogers CJ and Twyman RE: Barbiturate regulation of kinetic properties of the GABAA receptor channel of mouse spinal neurones in culture. J Physiol 417: 483-500, 1989.

19. Löscher W and Potschka H: Role of multidrug transporters in pharmacoresistance to antiepileptic drugs. J Pharmacol Exp Ther 301: 7-14, 2002.

20. Sisodiya SM, Lin WR, Harding BN, Squier MV and Thom M: Drug resistance in epilepsy: Expression of drug resistance proteins in common causes of refractory epilepsy. Brain 125: 22-31, 2002.

21. Maleki M, Sayyah M, Kamgarpour F, Karimipoor M, Arab A, Rajabi A, Gharagozli K, Shamshiri AR and Shahsavand AE: Association between ABCB1-T1236C polymorphism and drugresistant epilepsy in Iranian female patients. Iran Biomed J 14: 89-96, 2010.

22. Haerian BS, Lim KS, Mohamed EH, Tan HJ, Tan CT, Raymond AA, Wong CP, Wong SW and Mohamed Z: Lack of association of $\mathrm{ABCB} 1$ haplotypes on five loci with response to treatment in epilepsy. Seizure 20: 546-553, 2011. 